\title{
Aplicació dels principis bàsics de les màquines simples als regadius i usos tradicionals.
}

\author{
José Fenollar Moncho \\ IES Ribot i Serra (Sabadell) \\ jfenoll2@xtec.cat
}

Resum • Les màquines simples i els mecanismes de transmissió del moviment van sorgir per resoldre els problemes que plantejaven les activitats quotidianes en temps molt antics, entre elles la caça, la pesca o el transport d'objectes pesants, com la roda amb la utilització del carro, així com en el regadiu tradicional: la taona i la sènia. En aquest article els alumnes de batxillerat poden veure la utilitat d'aplicar els principis bàsics teòrics de les màquines simples de la matèria de tecnologia als regadius i usos tradicionals.

Paraules clau • carro, engranatges, màquines simples, sènia, taona.

\section{Application of simple machines basic principles to irrigation and traditional uses.}

\begin{abstract}
Simple movement machines and transmission mechanisms were created to solve the problems of everyday activities in ancient times, such as hunting, fishing or transporting heavy objects, such as the wheel with the use of carts, as well as in the traditional irrigated land: the taona and the senia. In this article, high school students can see the utility of applying the basic principles of simple machines of technology to irrigation and traditional uses.
\end{abstract}

Keywords $\cdot$ carriage, gears, simple machines, senia, taona. 


\section{INTRODUCCIÓ}

Arquímedes va establir els principis sobre la palanca, una frase universalment coneguda que ha passat a la història: "doneu-me un punt de suport $i$ mouré el món”, per indicar que la palanca és capaç de multiplicar la força. La palanca pot aixecar qualsevol pes, per molt gran que aquest sigui, sempre que es trobi un punt de suport adequat.

La palanca (figura 1) és una màquina simple, probablement la més coneguda. En la majoria dels casos, les màquines simples s'usen per multiplicar la força o per canviar la seva direcció; la idea és sempre que la feina demani menys esforç i que resulti llavors més senzill, i en ocasions també més segur. Podem afirmar que les màquines simples s'utilitzen per transformar o compensar una força resistent 0 aixecar un pes en condicions més favorables.

Les màquines simples van sorgir per resoldre els problemes que plantejaven les activitats quotidianes en temps molt remots, entre elles la caça, la pesca o el transport d'objectes pesants, com la roda amb la utilització del carro (figura 6), així com en el regadiu tradicional: la taona (figures 2,3 i 4) i la sènia (figures 8 i 9). Inicialment es van anar dissenyant certs estris, que després es van anar perfeccionant $i$ és així com van sorgir les primeres màquines simples. Es podria dir que aquestes primeres màquines van funcionar gairebé com una extensió de les mans humanes: van ser instruments de fusta per cavar, roques afilades per tallar i d'altres. Però sens dubte, van produir importants canvis en la història de l'home i en la seva relació amb el treball.

La tecnologia ha evolucionat, la societat ha avançat $i$ en ple segle XXI les màquines simples tenen un paper fonamental en la vida quotidiana de les persones $\mathrm{i}$ en el món industrial. Actualment, les màquines simples es fan servir per transformar $\mathrm{i} / \mathrm{o}$ compensar una força o resistència a l'hora d'elevar o moure un pes, d'aquesta manera es pot dur a terme el treball d'una manera més favorable i fàcil. Es tracta d'artefactes senzills que transformen un moviment (energia) en una altra acció i faciliten diverses tasques, que haurien de implicar l'ús de més força humana o animal, si no es comptés amb l'ajuda d'aquest tipus de dispositius. En el dia a dia es fan servir multitud de màquines simples com poden ser unes tisores, un carretó d'anar a comprar, un pla inclinat per superar desnivells, unes pinces per estendre la roba, unes alicates o qualsevol caragol.

Combinant màquines simples es construeixen màquines més complexes, que són utilitzades en múltiples aplicacions com, per exemple, per fabricar motlles per a articles de plàstic, en la construcció de cases i edificis, etc. (Joseph et al., 2017).

La tecnologia emprada per dissenyar i construir objectes o sistemes tècnics amb l'objectiu de resoldre problemes o satisfer necessitats, ha estat sempre present en el desenvolupament de la humanitat. En l'actualitat sembla que només hi ha màquines associades a dispositius tecnològics moderns (telèfons mòbils, ordinadors...) però la tecnologia ha estat sempre present en el desenvolupament de la humanitat, com per exemple la utilització de màquines més simples com la taona, el carro i la sènia, entre altres. En aquest article, és pretén que l'alumne pugui reflexionar sobre l'evolució de l'activitat tecnològica en la vida quotidiana dels usos tradicionals i de regadiu fins l'actualitat, així com que la tecnologia ha estat present des de lantiguitat, en aparells molts simples (carros, taona, sènia, tisores, alicates,..) fins avui amb aparells més moderns(ordinadors, cotxes, motors de reg,...). El que es pretén es posar en valor la relació amb tecnologies més antigues.

\section{OBJECTIUS}

Els objectius amb aquest article és que els alumnes de batxillerat puguen:

- Reflexionar sobre l'evolució de l'activitat tecnològica en la vida quotidiana dels usos tradicionals $i$ de regadiu entre altres, fins 「'actualitat.

- Descriure i aplicar les condicions d'equilibri estàtic en la resolució de problemes i situacions de cossos i màquines simples.

- Identificar i descriure el funcionament de màquines simples: palanca i roda, relacionats amb els regadius i usos tradicionals. 
- Identificar els mecanismes de transmissió del moviment més importants i descriure la seva funció i aplicacions.

- Determinar les característiques i els paràmetres geomètrics de les transmissions per engranatges utilitzats en la sènia.

- Calcular els paràmetres més importants de les transmissions: relació de transmissió i velocitats lineals i de rotació en funció de les seves característiques dimensionals.

- Determinar les característiques dinàmiques elementals en mecanismes de transmissió del moviment circular: parell.

\section{MÀQUINES SIMPLES}

Las màquines simples com la palanca (figura 1) i la roda (figura 5) s'utilitzen per amplificar forces; així s'aconsegueixen elevar o desplaçar cossos o càrregues pesants fent petits esforços. Cal recordar que, si el rendiment d'una màquina és del $100 \%$, el treball o energia que rep és el mateix que subministra. El treball que fem sobre una màquina simple es diu treball motriu i el que fan les càrregues per contrarestar, treball resistent (Joseph et al., 2017).

\section{La palanca}

La primera postulació matemàtica formal del principi de la palanca s'atribueix a Arquímedes. En l'àmbit dels avenços de la teoria de la palanca, s'hagué d'esperar a Leonardo da Vinci, que va estudiar-ne les diferents geometries. A Da Vinci se li atribueixen notables treballs sobre la palanca que encara avui continuen vigents. La palanca és una barra rígida que es recolza en un punt de suport o fulcre (figura 1).

Si s'apliquen forces sobre la barra s'originen moments que fan girar la barra en un sentit determinat i que en poden contrarestar d'altres que la farien girar en sentit contrari. Aleshores, perquè hi hagi equilibri, la suma de moments respecte al punt de suport ha de ser igual a zero (Joseph et al., 2017):

$$
\Sigma M(0)=0 \quad(1)
$$

En una palanca, el moment de la força $(F)$ que s'aplica és igual al producte d'aquesta per la distància mínima al punt de suport, i s'anomena braç de palanca. En conseqüència, perquè hi hagi equilibri, el braç de palanca ha de ser igual al moment resistent, és a dir, el que genera la força o resistència $(R)$ que es vol equilibrar (veure figura 1):

$$
F \cdot d_{1}-R \cdot d_{2}=0, \quad d^{\prime} \text { on } \quad F \cdot d_{1}=R \cdot d_{2}
$$

Aquesta és l'expressió matemàtica de la llei de la palanca que diu: força $(F)$ pel seu braç $\left(d_{1}\right)$ igual a resistència $(R)$ pel seu braç $\left(d_{2}\right)$.

\section{Taona o tahona}

La taona o tahona (figures 2,3 i 4) és un instrument amb una estructura de fusta que consisteix en un caixó molt llarg, sense tapadora, més ample d'un cap que de l'altre, que es posa per l'extrem estret dins l'aigua d'una sèquia o d'un bassot i l'altre fora, s'ompli d'aigua, es fa palanca (veure figura 1), es trau i es buida als bancals situats més amunt del nivell de l'aigua.

La seva procedència és probablement de l'àrab tāhūna, 'molí d'aigua', per comparació del moviment de la taona de regar amb el de la roda del molí accionada per l'aigua.
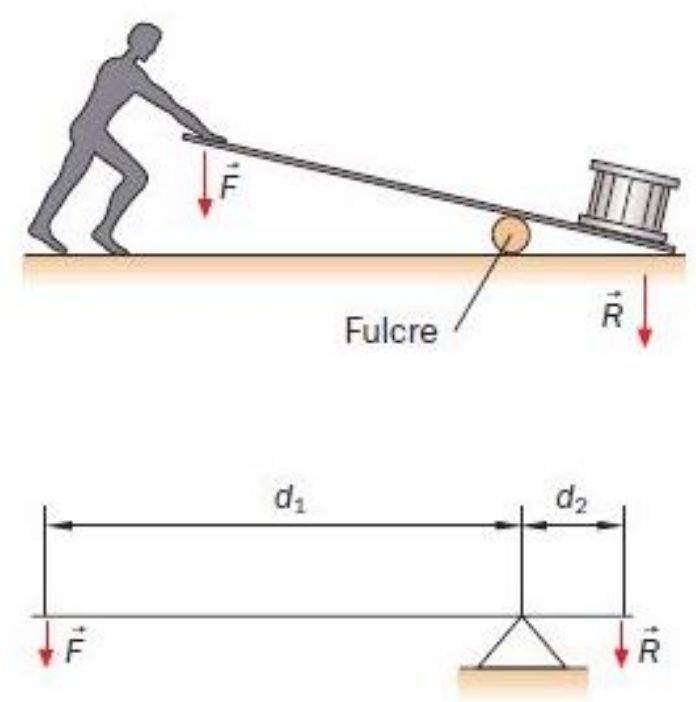

Figura 1: Forces que actuen sobre la palanca (Joseph et al., 2017). 


\section{Funcionament de la taona o tahona}

Per regar es deixa caure la part baixa dins l'aigua (A del dibuix de la figura 2 i $R$ en la figura 1); l'aigua entre per la porteta i ompli la part de la tahona que queda baixa l'aigua. Una persona tira de l'altra punta, ( $\mathrm{B}$ al dibuix de la figura 2 i $\mathrm{F}$ en la figura 1) cap a baix. La canal que en realitat és la tahona bascula cap a dins del camps i l'aigua corre per dins d'ella de la part $\mathrm{A}$ a la part $\mathrm{B}$, que està oberta i permet eixir l'aigua per regar el camp. I tornem a començar, perquè a cada moviment de tahona (moviment de palanca) era poca l'aigua i s'havia d'accionar moltes vegades l'aparell per poder omplir el camp i regar.

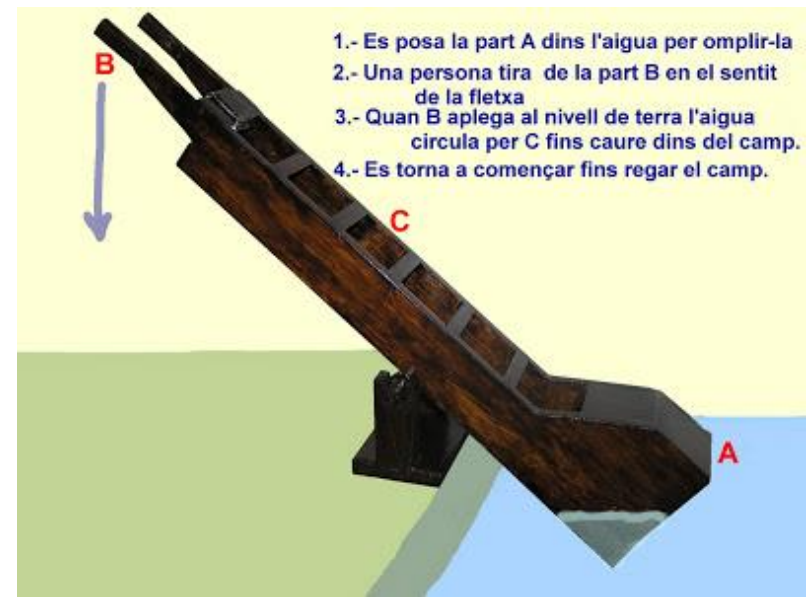

Figura 2. Maqueta de tahona obra de José María Carbonell Castells. Imatge de

http://polinyadexuquer.blogspot.com/search/label/agricu Itura.

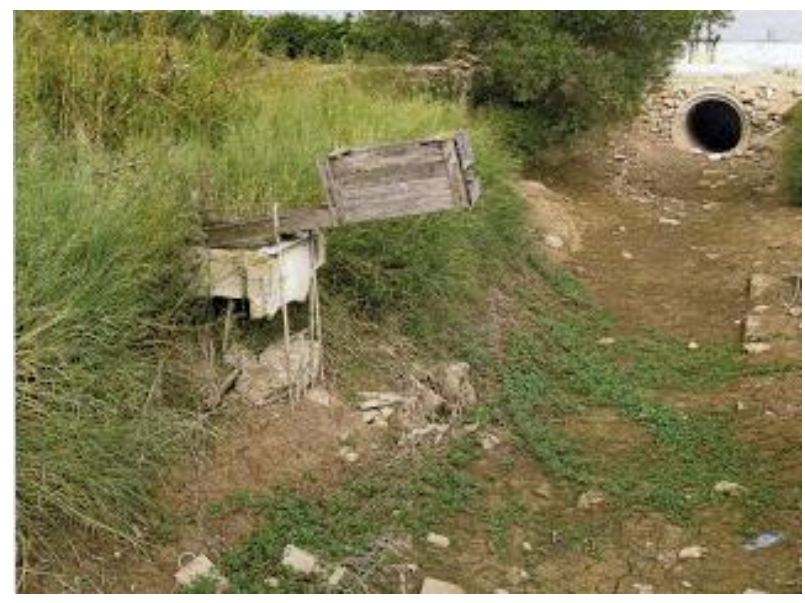

Figura 3. Tahona. Imatge de

http://polinyadexuquer.blogspot.com/search/label/agricu Itura.

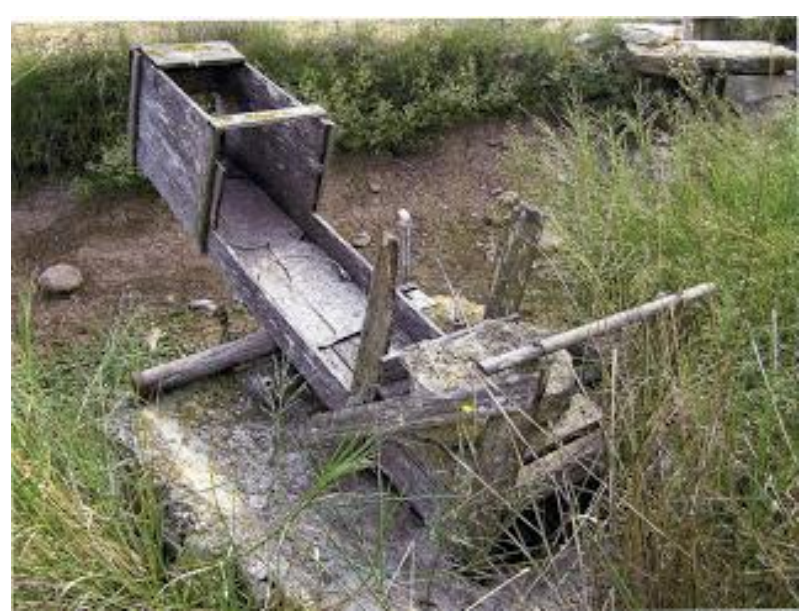

Figura 4. Tahona. Imatge de

http://polinyadexuquer.blogspot.com/search/label/agricu Itura.

\section{La roda}

Les aplicacions de la roda (figura 5) són molt nombroses; entre les quals, la primera segurament fou com a element de desplaçament de càrregues en el transport, com el carro (figura 6). Si una càrrega es desplaça sobre un vehicle de rodes en lloc de ser desplaçada arrossegant-la, en comptes de fricció es parla de rodolament. Per tal que una roda rodoli sobre una superfície ha d'existir una fricció entre totes dues; si no fos així la roda, en lloc de rodolar, patinaria. Ara bé, aquesta fricció es produeix perquè la roda o la superfície, o totes dues, es deformen com a conseqüència de la força que fa el pes (G) de la roda sobre la superfície. Per tant, si s'aplica una força suficient $F$ a l'eix de la roda, en direcció horitzontal, al llindar del rodolament o rodolament imminent, la normal $\mathrm{N}$ deguda al pes de la roda, s'avança una distància $\delta$ anomenada coeficient de rodolament. Llavors, si calculem els moments respecte del punt $\mathrm{O}$ (figura 5), tenim segons Joseph et al. (2017):

$$
\Sigma M(0)=0
$$

D`on

$$
F \cdot r_{r}=N . \delta_{r} d^{\prime} \text { on } F=\frac{N . \delta}{r_{r}}(N)
$$




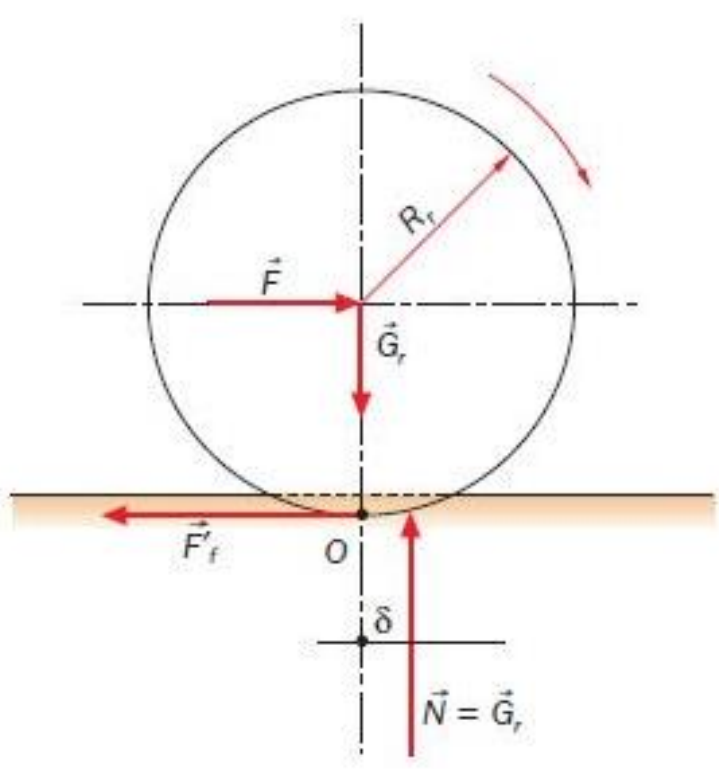

Figura 5: Diagrama del cos lliure d'una roda o corró, al llindar del rodolament o rodolament imminent (Joseph et al., 2017)

I per tal d' iniciar el moviment caldrà que:

$$
F \geq \frac{N . \delta}{r_{r}}(N)
$$

on

$\delta$ : coeficient de rodolament en metres $(m)$.

$\mathrm{F}$ : força a aplicar al centre de la roda en Newtons (N).

$\mathrm{N}$ : normal equivalent al pes $\left(\mathrm{G}_{\mathrm{r}}\right)$ de la roda en Newtons (N).

$r_{r}$ : radi de la roda en metres $(m)$.

El coeficient de rodolament no és adimensional i es mesura en metres. El seu valor varia des de $0,25 \cdot 10^{-3} \mathrm{~m}$, per a rodes d'acer sobre superfícies d'acer, com ara en el cas dels ferrocarrils, fins a $0,125 \mathrm{~m}$ per a rodes i superfícies toves.

\section{El carro}

Un carro (figura 6) és vehicle de tracció animal per a transportar càrrega, que consisteix en un marc o caixa, amb baranes o sense, proveït d'una perxa o de dues vares on van enganxats els animals i d'un fusell fixat a la part inferior, als extrems del qual giren lliures dues rodes. L'aparició dels primers carros va ser a l'antiguitat, cap al $3500 \mathrm{aC}$ a Mesopotàmia i, poc temps després, a Egipte (Bunch \& Hellemans, 2004). El seu declivi comença quan comença a generalitzar l'ús del

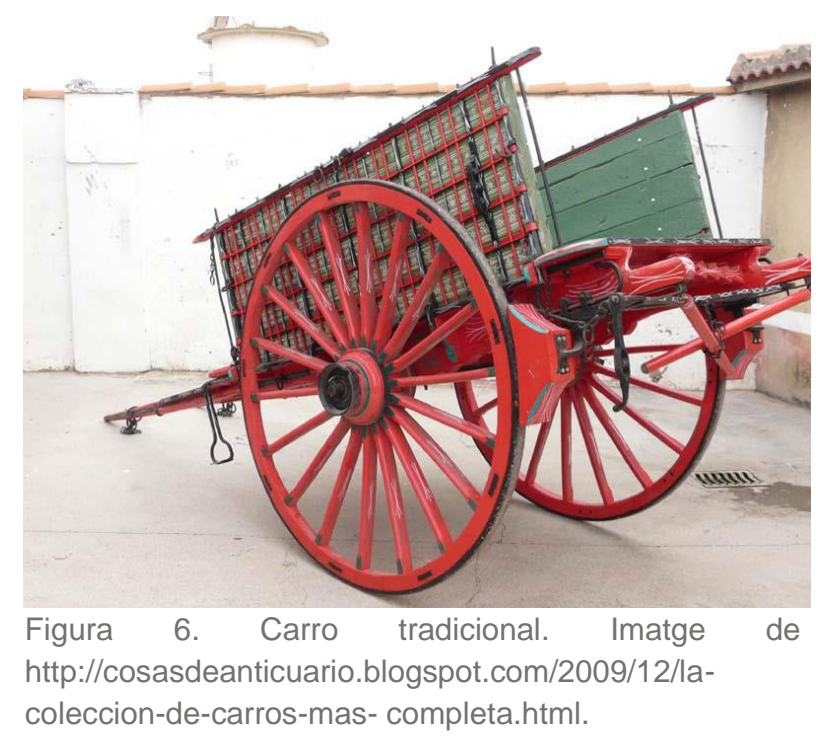

tractor, a partir de l'inici de la segona meitat de segle $X X$, el qual substituirà la força animal. Els carros són de mica en mica substituïts per remolcs, amb més capacitat, de quatre rodes $\mathrm{i} a \mathrm{mb}$ pneumàtics en lloc de rodes de fusta amb llandes de ferro.

\section{ENGRANATGE CÒNIC}

Els engranatges (figures 7 i 10) són els que transmeten el moviment entre dos eixos que es tallen. Els més usuals són els que tenen les dents rectes. S'obtenen a partir d'un con on es generen les dents. La secció de les dents és més gran a mesura que augmenta el diàmetre del con. En una transmissió, els vèrtexs imaginaris dels cons han de coincidir en un punt, d'aquesta manera s'assegura que el pas de les dents sigui igual (Joseph et al., 2017).

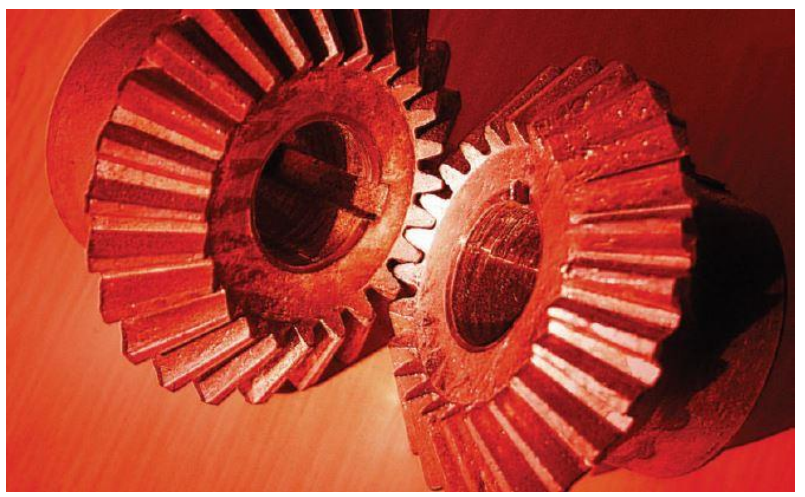

Figura 7. Engranatges cònics (Joseph et al., 2017). 


\section{Càlcul de velocitats i relacions de transmissió}

En les transmissions mitjançant engranatges, les velocitats entre l'entrada i la sortida es relacionen, com en el cas de la transmissió mitjançant corretja dentada o cadena, a partir de l'expressió (Joseph et al., 2017):

$$
w_{1} \cdot z_{1}=w_{2} \cdot z_{2}(6)
$$

on $\omega_{1}$ i $\omega_{2}$ són les velocitats angulars dels engranatges d'entrada i sortida, i $z_{1}$ i $z_{2}$, els nombres de dents dels engranatges respectius.

La relació de transmissió ( $I$ ) és la relació que hi ha entre la velocitat de sortida i la d'entrada. Coincideix amb la inversa de la relació del nombre de dents i també amb la inversa de la relació dels moments parells transmesos:

$$
i_{1 \rightarrow 2}=\frac{w_{2}}{w_{1}}=\frac{z_{1}}{z_{2}}=\frac{r_{1}}{r_{2}}
$$

El parell motor o simplement $(r)$ és el moment generat per dues forces paral-leles del mateix mòdul i sentit contrari. On:

$$
r_{1}=F \cdot r_{1} \quad i \quad r_{2}=F \cdot r_{2}
$$

\section{La sènia}

La sènia (figures 8 i 9) d'origen àrab, era una màquina que s'utilitzava per a treure aigua d'un pou. Aquesta paraula es troba documentada des de l'any 1054 i deriva de l'àrab seniya que a la vegada deriva de la paraula que en aquest idioma significa molí.

La sènia és una màquina per a elevar aigua subterrània, composta d'una roda horitzontal (rodet) amb braçols (engranatge), moguda per una bèstia (generalment rucs, mules o bous) que volta, i amb la qual engranen les dents d'una roda vertical (veure figures $9 \mathrm{i} 10$ ) que en rodar mou una sèrie de catúfols disposats al llarg d'un rest o cadena sens fi, la part inferior de la qual va submergida dins l'aigua del pou on la màquina està instal-lada.

La sènia és una de les màquines arcaiques que durant aquests cinquanta anys darrers han anat desapareixent. Esteses abans per tot allò on hi havia horts de regadiu, han estat suplantades per bombes hidràuliques, per molins, o almenys per formes modernitzades de la mateixa sènia. Aquesta en la seva forma autèntica és completament de fusta; poques se'n veuen ja que ho siguin, i això només a la regió valenciana i a les Balears; moltes han estat modernitzades a base de rodes i eixos de ferro (figura 10), i de cadena en lloc del rest de catúfols.

El nom català general és sínia o sènia; en valencià es diu també nòria, i aquest nom ja està documentat amb la forma nora en el segle XV. La cavitat d'on la sínia treu l'aigua s'anomena senial o pou en València, i sínia a les Balears. Al voltant de la sènia el terreny sol esser un poc elevat, formant un monticle margenat de terra 0 de pedres, que s'anomena mota o cintell (Balears) i andàmit (Ribera del Xúquer). L'eix vertical del rodet s'anomena arbre que és aquella peça, generalment cilíndrica, capaç de transmetre un moviment circular $\mathrm{i}$, per tant, també un moment o parell motor; el rodet és una roda dentada que volta en sentit horitzontal (veure les figures 8 i 9).

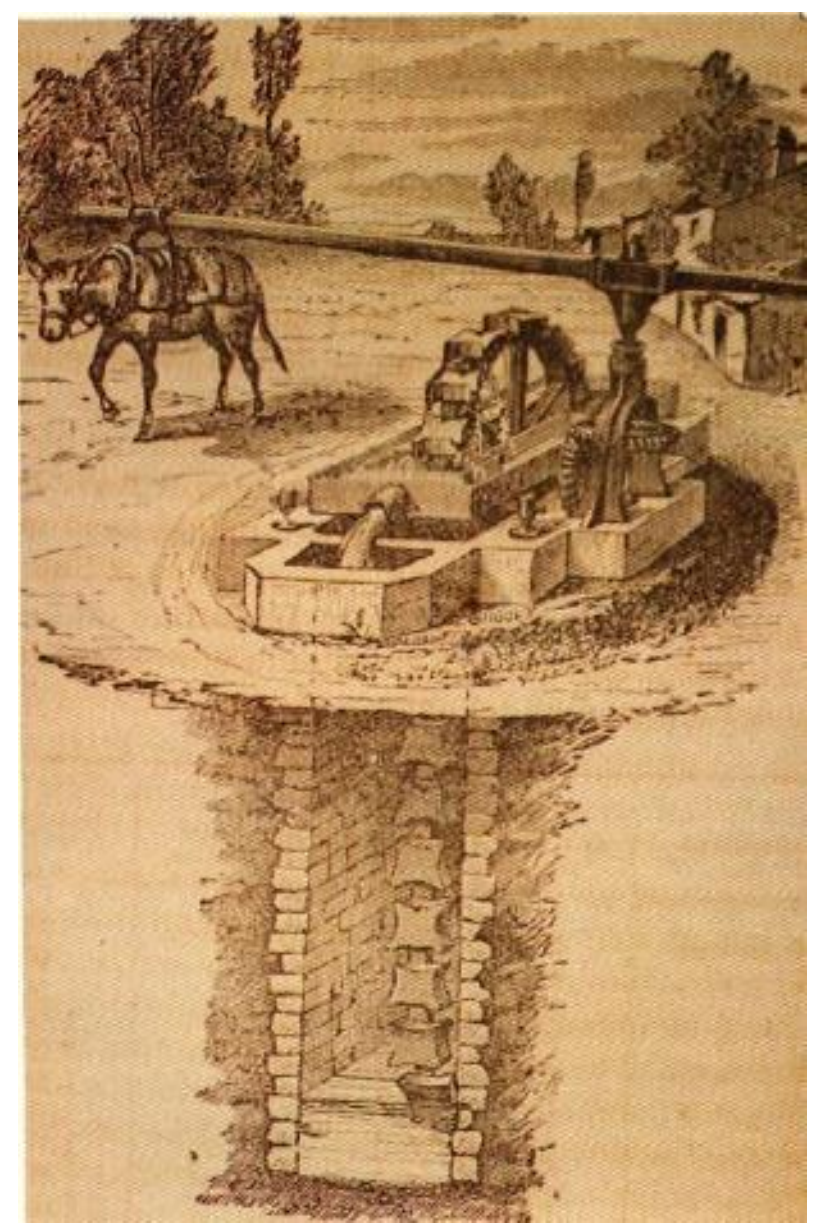

Figura 8. Sènia. 


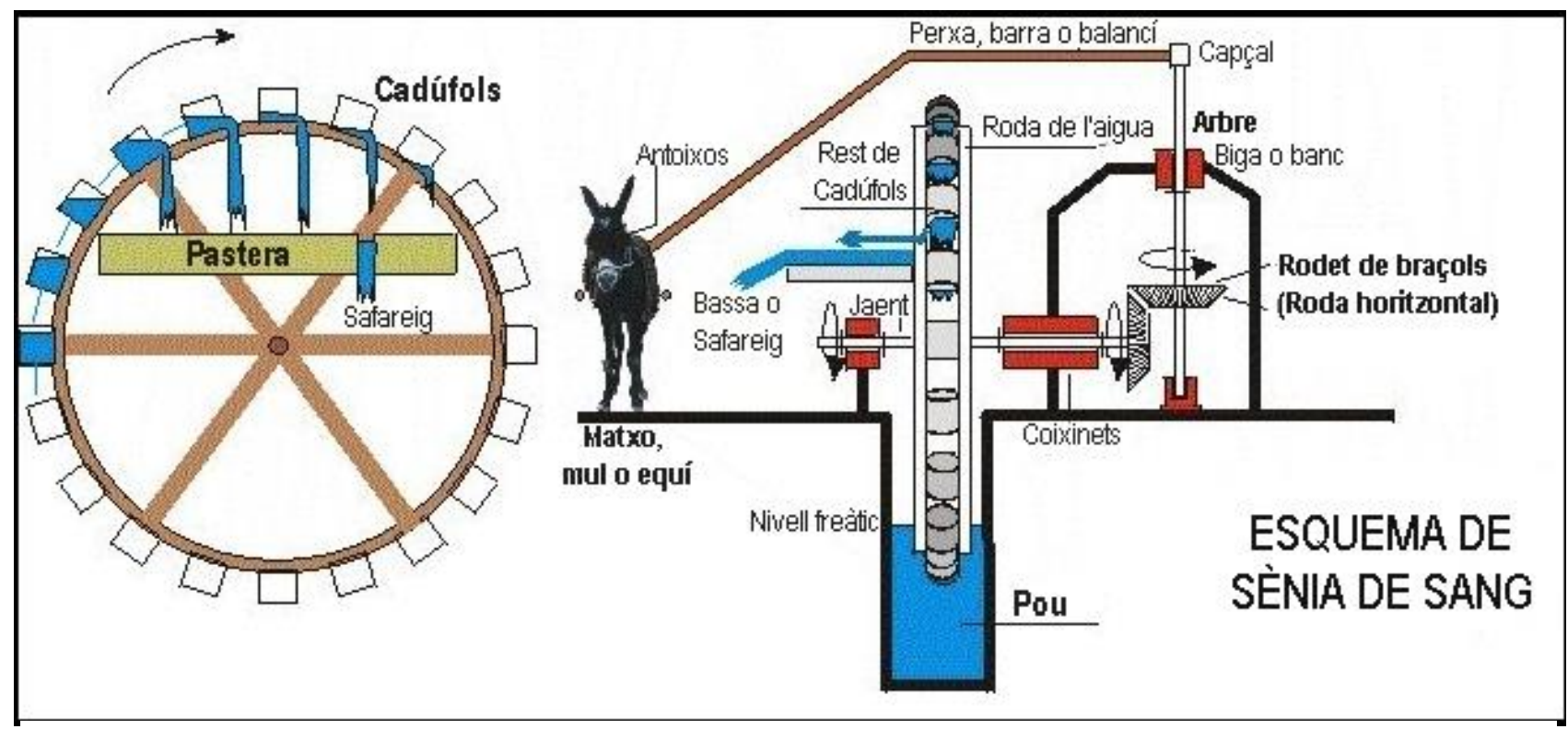

Figura 9. Esquema d`una sènia. Imatge de https://www.catimenu.com/senia.htm.

\section{CONCLUSIONS}

La tecnologia, entesa com el conjunt d'habilitats i coneixements científics i tècnics emprats per l'ésser humà per pensar, dissenyar i construir objectes o sistemes tècnics amb l'objectiu de resoldre problemes 0 satisfer necessitats col-lectives o individuals, ha estat sempre present en el desenvolupament de la humanitat, com per exemple la utilització de la taona, el carro i la sènia. Conforme ha anat evolucionant la tecnologia, han anat evolucionant tots els camps que ens han permès aconseguir l'actual societat de benestar $\mathrm{i}$ això ha contribuït a configurar el món que coneixem $\mathrm{i}$, amb certesa, contribuirà a configurar el paisatge del futur. Així, els alumnes del nivell de batxillerat poden veure amb aquest article les aplicacions de les fórmules teòriques estudiades en classe de les màquines simples (la roda i la palanca) i els mecanismes de transmissió (engranatges) de la matèria de tecnologia, concretament als regadius i usos tradicionals dels nostres avantpassats. També poden identificar i descriure el funcionament de màquines simples com la palanca i la roda aplicat al funcionament de la taona $\mathrm{i}$ el carro, així com identificar els mecanismes de transmissió del moviment (engranatge cònic) més importants i descriure la seva funció $\mathrm{i}$ aplicacions com el funcionament de la sènia. Al mateix temps, poden aprofundir en el coneixement i l'estima dels elements específics de la història i la cultura del seu territori perquè sigui valorada i respectada com a patrimoni propi. També pot servir per valorar críticament l’evolució de l'activitat tecnològica en la vida quotidiana i la

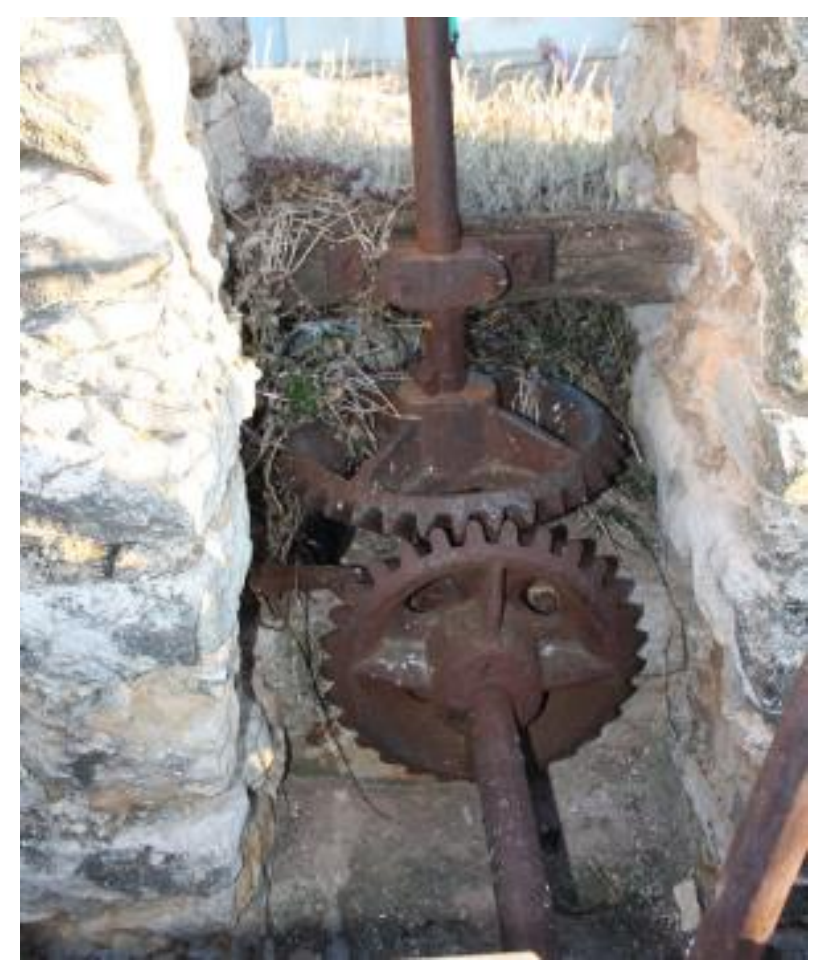

Figura 10. El rodet (roda horitzontal) fa girar la roda vertical que transmet el moviment a la roda de catúfols. Imatge de https://www.catimenu.com/senia.htm. 
qualitat de vida de la societat. Així com, poden valorar que la tecnologia ha estat present des de l'antiguitat amb màquines més simples i no només en I'actualitat més moderna amb aparells més sofisticats.

\section{BIBLIOGRAFIA}

Bunch, B. H. \& Hellemans, A. (2004). The history of science and technology: a browser's guide to the great discoveries, inventions, and the people who made them, from the dawn of time to today. Houghton Mifflin Harcourt, p.31.
Joseph J., Hoyos R.,Garravé J., Garófano F. \& Vila F. (2017). Tecnologia Industrial. 1r batxillerat. Editorial McGraw Hill education.

Nota: Per trobar més informació sobre la taona i la sènia, es poden consultar les següents pàgines web:

\section{La taona:}

http://polinyadexuquer.blogspot.com/search/label/ agricultura.

\section{La sènia:}

https://www.catimenu.com/senia.htm. 